IZA DP No. 6099

The Intergenerational Transmission of Human Capital: Exploring the Role of Skills and Health Using Data on Adoptees and Twins

Petter Lundborg

Martin Nordin

Dan Olof Rooth

October 2011 


\title{
The Intergenerational Transmission of Human Capital: Exploring the Role of Skills and Health Using Data on Adoptees and Twins
}

\author{
Petter Lundborg \\ Lund University, VU University Amsterdam, \\ Tinbergen Institute, HEP, CED and IZA \\ Martin Nordin \\ Lund University and HEP \\ Dan Olof Rooth \\ Linnaeus University, Lund University, \\ CED, CReAM and IZA \\ Discussion Paper No. 6099 \\ October 2011 \\ IZA \\ P.O. Box 7240 \\ 53072 Bonn \\ Germany \\ Phone: +49-228-3894-0 \\ Fax: +49-228-3894-180 \\ E-mail: iza@iza.org
}

\begin{abstract}
Any opinions expressed here are those of the author(s) and not those of IZA. Research published in this series may include views on policy, but the institute itself takes no institutional policy positions.

The Institute for the Study of Labor (IZA) in Bonn is a local and virtual international research center and a place of communication between science, politics and business. IZA is an independent nonprofit organization supported by Deutsche Post Foundation. The center is associated with the University of Bonn and offers a stimulating research environment through its international network, workshops and conferences, data service, project support, research visits and doctoral program. IZA engages in (i) original and internationally competitive research in all fields of labor economics, (ii) development of policy concepts, and (iii) dissemination of research results and concepts to the interested public.
\end{abstract}

IZA Discussion Papers often represent preliminary work and are circulated to encourage discussion. Citation of such a paper should account for its provisional character. A revised version may be available directly from the author. 


\section{ABSTRACT}

\section{The Intergenerational Transmission of Human Capital: Exploring the Role of Skills and Health Using Data on Adoptees and Twins ${ }^{*}$}

In this paper, we focus on possible causal mechanisms behind the intergenerational transmission of human capital. For this purpose, we use both an adoption and a twin design and study the effect of parents' education on their children's cognitive skills, non-cognitive skills, and health. Our results show that greater parental education increases children's cognitive and non-cognitive skills, as well as their health. These results suggest that the effect of parents' education on children's education may work partly through the positive effect that parental education has on children's skills and health.

JEL Classification: I12, I11, J14, J12, C41

Keywords: intergenerational transmission, human capital, education, health, cognitive skills, non-cognitive skills, adoptees, twins

Corresponding author:

Petter Lundborg

Lund University

Department of Economics

P.O. Box 7082

22007 Lund

Sweden

E-mail: petter.lundborg@nek.lu.se

\footnotetext{
* The authors thank Anders Björklund, Paul Devereux, Peter Fredriksson, Lars Kirkebøen, Mårten Palme, Erik Plug, Marte Rønning, Jonas Vlachos and seminar participants at UCD Dublin, Lund University, Stockholm University, Statistics Norway, and the EALE 2011 conference for useful comments and suggestions. A research grant from the Centre for Economic Demography (CED) at Lund University is gratefully acknowledged.
} 


\section{Introduction}

There is a strong and well known correlation between parents' human capital and that of their children. A recent literature has established that at least part of this transmission of human capital seems to reflect a 'nurturing' effect of parents' education on their children's education (for recent overviews of the literature, see Black and Deveraux 2010, Björklund and Salvanes 2010, and Holmlund et al. 2010). This literature has mostly been based on studies of adopted children and children of twin parents (e.g. Behrman and Rosenzweig 2002; Sacerdote, 2002; Plug, 2004; Björklund et al. 2006; Holmlund et al., 2010). ${ }^{1}$

Much less is known about the causal mechanisms involved in the intergenerational transmission of human capital. Do the estimates reflect, for instance, that more educated parents get healthier children, who, in turn, go on to obtain more schooling? A growing literature points to the importance of early "health capital" for education and earnings (see Currie 2009 and Almond and Currie 2010 for recent overviews). Or do the estimates reflect that more educated parents get smarter children or children with greater social skills? Studies by James Heckman and others emphasise the importance of skill acquisition early in life for later life outcomes (Heckman et al. 2006).

In this paper, we focus on possible mechanisms behind the intergenerational transmission of human capital. For this purpose, we use both an adoption and a twin design and study the effect of parents' education on their children's cognitive skills, non-cognitive skills, and health. This allow us to shed some light on what is reflected in previous twin and adoption-based estimates on the transmission of education across generations. If parental schooling affects child outcomes such as skills and health, this also provides a possible explanation to how the intergenerational transmission of education arises.

We believe that improving the understanding of the underlying mechanisms that explains the transmission of education across generations is a natural next step in the literature. ${ }^{2}$ First of all, opening the black box of possible causal mechanisms would increase our understanding of what it is that welleducated parents transmit to their children. This could be useful information for policy-makers. For instance, policies that increase the level of education in society could be considered as more valuable if they also improve the education of people's offspring through increasing the offspring's skills and the health, rather than only through improving their study results in a narrower sense.

Second, policies that encourage people to invest in education may be more desirable to society if education promotes intergenerational mobility through

\footnotetext{
${ }^{1}$ There is also a small number of IV-studies, where changes in compulsory schooling laws have been used for identification (see for instance Black et al. 2005; Holmlund et al. 2010).

${ }^{2}$ The importance of understanding the mechanisms is also argued in a recent overview by Black and Deveraux (2010), where the authors write: "The focus of current research is on establishing a link between parent and child education; understanding the underlying mechanisms is a clear direction for future research." A similar view is expressed by Holmlund et al. (2010), who conclude that: "From our perspective, the roadmap for future research lies in a better understanding of the mechanisms that explain how parental schooling is passed on to the next generation."
} 
improving the skills and health of children, rather than through for instance only promoting access to higher education or through nepotism. ${ }^{3}$

Third, knowledge about the underlying mechanisms would also allow policy-makers to directly target those mechanisms in order to reach policy goals such as increased intergenerational mobility. ${ }^{4}$ Finally, increased knowledge about the mechanisms is of interest from a child development perspective. Improving children's skills and health is often regarded as an important goal in itself for society and understanding the role that parental education plays in the "child quality production function" should therefore be useful for policymakers.

Our results show that greater parental education increases children's cognitive and non-cognitive skills, as well as their health. Moreover, the estimates are rather similar using both the adoption and twin design. In addition, we obtain some pronounced gender differences, where fathers' education matters more for the formation of cognitive and non-cognitive skills, whereas mothers' education matter more for the child's health.

We also show that our estimates appear very reasonable, given the results obtained in previous studies on the intergenerational transmission of human capital and on the returns to early life characteristics. Focusing only on cognitive and non-cognitive skills, we show that the effect of parental education on such child skills could explain at least half of the causal effect of parental schooling on children's schooling obtained in previous studies. Our results thus suggest that skills and health early in life may be important mechanisms through which the intergenerational transmission of education arises.

The paper proceeds as follows. The next section reviews some of the relevant literature on the intergenerational transmission of human capital. In section 3, we describe the data used in the study. In Section 4, we then describe and discuss the two empirical strategies used in this paper; the adoption design and the twin design. Section 5 presents the results and contrasts the results obtained from the two alternative identification strategies. In Section 6, we summarize our findings and draw some conclusions.

\section{Previous literature}

We start this section by first reviewing some of the recent studies that use an adoption or twin design to study the intergenerational transmission of education. We then comment on the few studies that have explored possible causal mechanisms, using an adoption or twin design. Finally, we provide a brief

\footnotetext{
${ }^{3}$ This also relates to the discussion on the socially optimal level of intergenerational mobility (Black and Devereaux 2010). In order to determine a socially optimal level of mobility, it is crucial to understand the underlying causes of the intergenerational transmission of education. A society may be less willing to accept low mobility if it mainly results from nepotism rather than from skills that children of well-educated parents get from their parents.

${ }^{4}$ For instance, if parents' education primarily affects children's education by improving child health outcomes, health interventions targeted toward low-educated families could weaken the link between parents' and their children's education. The same could be said for programs aimed at improving skills early in life, such as the Perry pre-school program (see Heckman et al. 2006).
} 
review of some of the IV-literature that may yield some insights into possible mechanisms. Note that when we report estimates for the intergenerational transmission of human capital it is, unless otherwise stated, from specifications including fathers' and mothers' education separately, i.e. not accounting for assortative mating.

In the earlier adoption studies by Bruce Sacerdote (2000, 2002), data on Korean adoptees in the U.S was used to estimate the relationship between parents' years of schooling and children's schooling. He found that one additional year of schooling of the mother and of the father increased the children's years of schooling by .22 and .16 , respectively. ${ }^{5}$ Larger estimates were obtained by Plug (2004), using a sample of U.S adoptees. When controlling for adoptive fathers' education, however, the effect of mothers' education was no longer significant, whereas the effect of fathers' education remained unaltered when controlling for the spouse's education.

Later adoption studies usually obtain smaller 'nurturing' effects. Sacerdote (2007) obtained an estimate for mothers' education of .09, using data on Korean adoptees who were randomly assigned to families. ${ }^{6}$ Smaller effects, 0.07 for mothers and 0.11 for fathers, were also reported in the novel study by Björklund et al. (2006), where data on both the biological and adoptive parents of adopted children were used. For adoptive mothers, the effect decreased dramatically when controlling for spouse's education, thus confirming earlier results by Plug (2004).

A number of recent adoption studies, using data from Scandinavian countries, in general agree with the estimates obtained in Sacerdote (2007) and Björklund et al. (2006). In Holmlund et al. (2010), using data on both internationally adopted children and children adopted within Sweden, similar effects were obtained for both mothers' and fathers' education with no estimate being larger than 0.11 for children adopted in Sweden and 0.04 for international adoptees. ${ }^{7}$

In addition to the adoption studies, there has been a small number of twin studies on the intergenerational transmission of education. Using data on monozygotic twin parents, Behrman and Rosenzweig (2002) showed that no significant association between mothers' schooling and children's schooling remained when genes and common environment were accounted for. The effect of fathers' education was still significant, however, with an estimate of 0.36 .

Holmlund et al. (2010) also found that fathers' education mattered more, using a sample of pooled MZ and DZ twins, but with a smaller point estimate of 0.12 . Using Norwegian data on pooled MZ and DZ twins, Pronzato (2010) found larger effects of mothers' education, being around 0.10, compared to previous twin studies but still obtained the result that fathers' education mattered more $(0.16){ }^{8}$

\footnotetext{
${ }^{5}$ There is also an even earlier study by Dearden et al. (1997) that uses data on 41 adopted children from the British NCDS data. The results suggest even larger estimates of the intergenerational transmission of education compared to Sacerdote (2000, 2002).

${ }^{6}$ In a footnote, Sacerdote (2007) reports that similar results were obtained for fathers' education.

${ }^{7}$ Using school performance as an outcome, similar estimates were also obtained in a Norwegian context, using data on Korean adoptees (Haegeland et al. 2010).

${ }^{8}$ Haegeland et al (2010), studying school performance, found that fathers' education
} 
Contrasting evidence was obtained in Amin et al. (2011a), where the results showed that only mothers' education mattered, when using a sample consisting of MZ twins only. Moreover, this effect was driven completely by the effect of mothers' schooling on their daughter's schooling, where one additional year of mother's schooling increased daughter's schooling by 0.10. Moreover, in Bingley et al. (2009), where data on Danish MZ twins were used, the importance of mothers' education became larger in more recent cohorts.

There are also a few IV-studies on the topic, such as Black et al. (2005). Using a reform of the Norwegian schooling system as an instrument, they find no causal relationship between the father's education and the child's education level. For mother's they report a small effect on the son's education (but not on the daughter's). Similar IV-results were obtained by Holmlund et al. (2010), where mothers' education were found to be slightly more important. For an overview of IV-studies using other educational outcomes of the children, such as grade repetition etc, see Holmlund et al. (2010).

Our overall conclusion from the studies cited above is that there seems to exist a nurturing effect of parents' education, although more recent adoption and twins studies have estimated this transmission to be rather small, although not negligible. We next review the small literature using a twin or adoption design that have provided estimates on the causal effect of parents' education on children's outcomes, such as health and skills. These studies provide results that may be informative on the causal mechanisms involved in the intergenerational transmission of education.

In Sacerdote (2000), the relation between parents' years of schooling and children's cognitive test scores was estimated for a small sample of Korean adoptees in the U.S. ${ }^{9}$ The results suggest a significant nurturing effect of both mothers and fathers' education. In both cases, the estimates are about half the size compared to the estimates obtained in the control group of own-birth children. In Sacerdote (2007), the relation between mothers' education and children's BMI and drinking behaviour was estimated. For both outcomes, the effect of adoptive mothers' education is small and insignificant.

Using Chinese data, Chen and Li (2009) estimate the effect of mothers' education on children's height-for-age and find the effect to be of similar size for both adoptive mothers and own-birth mothers. The similarity of the results for adopted children and own-birth children suggests that the relationship between parental education and child height is primarily caused by parental nurturing and not by genetics (the estimates suggest that about $80 \%$ of the relationship could be attributed to nurture). ${ }^{10}$

mattered more for the child's exam scores.

${ }^{9}$ Sacerdote (2000) also uses a sample of adoptees from the British NCDS. For the analysis of the effect of fathers' years of schooling, the sample is very small, 81 children, and the effect on various child test scores at age 7 is imprecisely estimated and always insignificant. In addition, data on 117 adoptees from the Colorado adoption project is used to estimate the effect of adoptive mothers' education on child test scores at ages 6 and 7 . The estimates are insignificant and a lot smaller than the corresponding estimates for the effect of the biological mother's education.

${ }^{10}$ The large nurturing component obtained by Chen \& Li (2009) contrasts greatly with the results discussed above using adopted children to study the intergenerational correlation in schooling. The relatively greater role of nurture versus nature is also somewhat surpris- 
The only twin study on the relationship between parental education and child health outcomes that we are aware of is a working paper by Bingley et al. (2009). They use Danish data and estimate the effect of parental schooling on the birth weight of the offspring. The results show that mothers' schooling increase the birth weight of their offspring but that fathers' schooling have no effect.

Besides the adoption and twin studies on the relation between parents' education and child outcomes other than education, there is also a small IVliterature on the topic. ${ }^{11}$ The first IV study on the topic appears to be Currie and Moretti (2003), who used the expansion in the number of colleges in the US between 1940 and 1996 as an instrument for mothers' schooling. They found that the increase in college attendance of women improved children's health, in terms of birth weight and gestational age and led to less smoking among mothers.

In a study using UK data, Lindeboom et al. (2009) used the compulsory schooling reform in 1947 in Britain to estimate the causal effect of schooling on child health. They found no evidence of a causal effect of parental schooling on child health outcomes at birth and at ages 7, 11, and 16. Chevalier and Sullivan (2007), however, found that the reform had heterogeneous effects and that the most impacted groups experienced larger changes in infant birth weight.

Carneiro et al. (2007) used U.S data and instrumented mothers' education with the presence of colleges at age 17 in the state of residence and with local labor market conditions. They found a strong effect of maternal education on child cognitive outcomes, but also on measures of behavior problems.

Finally, McCrary and Royer (2011) combined data on exact birth dates and age-at-school entry policies in the spirit of Angrist and Kreuger's quarter of birth instrument. Using data on all births in California during the years 1989-2002, and using birth date as an instrument for schooling, they find no evidence of a causal effect of schooling on infant health outcomes.

The literature review above suggests that there is rather mixed evidence regarding the causal effect of parental schooling on child outcomes such as health and cognitive skills in developed countries. ${ }^{12}$ In a comprehensive sur-

ing, given that the average age of the adoptive children at follow-up is only 27.5 month, which means that the "nurturing period" is relatively short. The results may thus suggest that nurturing factors are more important for children's health development in developing countries, but less important for educational attainment in developed countries.

${ }^{11}$ Note, however, that the results from this literature may be hard to generalize to the twin and adoption literature, since the IV-estimates reflect Local Average Treatment Effects, where the instruments used normally affect people at the lower end of the educational distribution, while results using adopted children effectively exploits variation in education in a group of well-educated parents. The twin design exploit differences in education between twin parents, where the differences are often found to be quite evenly distributed across the education distribution.

${ }^{12}$ There also exist some studies in a developing country context, where the effect of parental education is ususally found to be significant. Breierova and Duflo (2004), for instance, exploited the primary school construction program in Indonesia during the 1970s. During this period, a large number of new schools were constructed but the intensity of the construction program varied across the districts in Indonesia. Using program intensity as an instrument for schooling, they find that parents' schooling have a negative effect on infant 
vey on the literature on children's health and parental socioeconomic status, Currie (2009) concludes that it is still difficult to prove that the relationship between parental background and children's health is a causal relationship and that more research is needed. It could be noted, though, that there is some agreement between the IV-studies and the studies using an adoption and twin design. Both Bingley et al. (2009), Currie and Moretti (2003), and Chevalier and Sullivan (2007) find evidence that maternal education affects birth weight. Moreover, both Carneiro et al. (2007) and Sacerdote (2000) find effects on cognitive outcomes. ${ }^{13}$

\section{Data}

For the purpose of this study, we merged a number of different registers. This includes the Register of the Total Population (RTB, with information on birth date, date of immigration, sex, country of birth, and parents' country of birth), the Multi Generation Register (Flergenerationsregistret, with identification of siblings on the mothers side through a family ID), the Swedish National Service Administration, the Swedish Register of Education (UREG), the National Tax Records, and the Swedish Twin Registry (with information on twin zygosity).

We identify adopted children through an adoption indicator that is available in the RTB-register from Statistics Sweden. From this register, we select all male foreign-born adoptees born between 1965 and 1978. In our sample, most adopted children came from South Korea (24\%), India (14\%), Chile (10\%), Thailand (9\%), Colombia (7\%) and Sri Lanka (6\%). These countries constitute $70 \%$ of the countries in our sample.

In order to avoid the risk that some foreign-born adoptees are adopted by relatives, which would create a genetic link, we only include adoptees adopted by Swedish-born parents. By further restricting the sample to those who have enlisted to the military, and who have non-missing data on parental education and on our outcome measures, our sample of adoptees varies between 3,375 and 3,741, depending on the outcome studied.

Our twin sample consists of all children to twin parents that were born between 1950-1978 and who have enlisted. ${ }^{14}$ In order to determine zygosity of the twins, we have merged our data with zygosity information from the

\footnotetext{
mortality.

${ }^{13}$ There are also a number of studies that estimates the relationship between various outcomes across generations, where the goal is not to establish causality, but where the results may still point to potentially important mechanisms for the intergenerational transmission of education. These includes, for instance, Black et al. (2009), Anger and Heineck (2009), Grönqvist et al. (2010), and Björklund et al. (2010), who all study the transmission of IQ across generations, and Lindqvist \& Hjalmarsson (2010) and Lindqvist \& Hjalmarsson (2011a), who study the intergenerational transmission of crime and drunk driving. In a recent paper, however, Lindqvist \& Hjalmarsson (2011b) use an adoption design, including both information on the adopted and biological parents, to study the intergenerational transmission of crime. Moreover, Amin et al. (2011b), studies the intergenerational transmission of income, using a twin design.

${ }^{14}$ Note that for adopted children, the sample only includes those born 1965 and onwards. The reason is that there were almost no international adoptions taking place in Sweden before 1965 .
} 
Swedish twin registry. In this manner, we are able to determine zygosity for $82 \%$ of the parents in our dataset. ${ }^{15}$ Our dataset includes between 2,983 and 3,216 children of monozygotic twin parents, depending on the outcome studied.

Our third sample consists of the population of "own-birth" sons, born during the periods corresponding to the periods used in the adoptee and twin samples. With this sample, we are unable to provide "baseline" estimates for a sample of sons with biological parents. We will then contrast these results with the ones obtained when breaking the genetic link through the adoption and twin design. Restricting the sample of own-birth sons to those with non-missing observations on parental education gives us between 851,128 and 903,891 observations, again, depending on the outcome studied.

In our empirical analyses, we focus on three set of outcomes; cognitive skills, non-cognitive skills, and health. These are measured at age 18, during the military enlistment tests. It should be noted that during our study period, in principle every male Swedish citizen enlisted for the military when turning 18. Enlistment was mandatory and there is very little attrition in the data. Refusal to enlist leads to a fine, and eventually to imprisonment. Individuals are only exempted from enlistment if they are imprisoned, if they have ever been convicted for heavy crimes (which mostly concerns violence-related and abuse-related crimes), or if they are in care institutions and are deemed to be unable to function in a war situation. During our study period, the annual cohort size of men turning 18 was about 50,000. Per cohort, around 1,250 (i.e., $0.25 \%$ ) were exempted from enlistment. ${ }^{16}$

Cognitive skills are measured using a test similar in style to the AFQT in the US. The test is called the Enlistment Battery 80 and includes four separate tests; Instructions, Synonyms, Metal Folding and Technical Comprehension. The separate scores of these tests are aggregated into a standard composite measure calculated by the military enlistment service. In our analyses, we use a normalized version of this score.

Non-cognitive skills are measured through interviews carried out by certified psychologists employed by the Swedish army. The ultimate purpose of the interview is to evaluate the conscript's ability to perform military service and to function in a war situation. This is achieved through an assessment of the enlistee's psychological stability and endurance, capability of taking initiatives, responsibility, and social competence. The assessment results in a composite enlistment score of non-cognitive skills, ranging from 1 to 9 , which we then normalize in our analyses.

Though the original purpose of the non-cognitive skill measure used here is to evaluate peoples' suitability to serve in a war situation, the character traits

\footnotetext{
${ }^{15}$ The twin registry determines zygosity based on survey questions regarding co-twin similarity. The method used has been found to classify twins with an accuracy of $95 \%$ or more (see Lichtenstein, 2002).

${ }^{16}$ Note also that the incentives to deliberately underperform at the enlistment tests are rather limited. The reason is that, during our study period, the results of the tests had no impact on the probability of doing military service or not, since almost all people that enlisted during our study period also completed military service. Instead, the test results merely influenced the individual's placement within the army, meaning that poorer results typically led to a less qualified and meriting placement.
} 
valued by the military psychologists are similar to the traits usually included in measures of non-cognitive skills. The measure has also been found to be a strong predictor of adult earnings, independently of cognitive skills (Lindqvist and Vestman 2010).

We consider two health outcomes in our empirical analyses; a measure of overall health and height. ${ }^{17}$ The former is an unidimensional global health measure, which is based on the severity of the individual's health conditions (both physical and mental) and which is used by the military to determine the enlistees suitability with respect to type of military service. In our analyses, we transform their ordered categories into a 13-step scale, ranging from worst possible health to perfect health. The measure of height is taken by the staff at the enlistment offices and we thus have none of the problems encountered when using self-reports on height.

Table 1 reports descriptive statistics for our three samples; own-birth sons, adopted sons and own-birth sons with a monozygotic twin-parent. Whereas mean health is similar in the group of own-birth children and the children of twin parents, adoptees have substantially worse health. Moreover, the height of adopted sons is, on average, considerably shorter than the height of ownbirth sons (with or without a twin parent). Finally, adoptive parents are significantly more educated than the parents of own-birth sons and adopted sons have lower cognitive and non-cognitive test scores compared to own-birth sons.

\section{Empirical model}

The typical reduced form equation used to estimate the intergenerational transmission of human capital from a parent $p$ to a child $c$ can be written:

$$
Y^{c}=\alpha+\delta S^{p}+\Gamma g^{p}+\gamma f^{p}+v^{c} .
$$

In this paper, $Y^{c}$ represents child outcomes, such as cognitive and noncognitive skills and health, whereas $S^{p}$ represents the schooling of the parent. Moreover, $g^{p}$ represents any genetic endowments that are passed on from the biological parent to the child, whereas $f^{p}$ represents any non-genetically transmitted characteristic of the parent other than schooling, such as child-rearing skills. Unobserved child-specific factors are denoted $v^{c}$. The $\delta$ coefficient measures the causal effect of parental education, $S^{p}$, on child outcomes. The $\Gamma$ and $\gamma$ coefficients measure the extent to which genetic endowments and nongenetic endowments are transmitted to the child. As shown by Holmlund et al. (2010), the least-square estimator of $\delta$ can be written as:

$$
p \lim \widehat{\delta}=\delta+\Gamma \frac{\operatorname{cov}\left(S^{p}, g^{p}\right)}{\operatorname{var}\left(S^{p}\right)}+\gamma \frac{\operatorname{cov}\left(S^{p}, f^{p}\right)}{\operatorname{var}\left(S^{p}\right)}
$$

Thus, in order to identify $\delta$, we need $\frac{\operatorname{cov}\left(S^{p}, g^{p}\right)}{\operatorname{var}\left(S^{p}\right)}=0$ and $\frac{\operatorname{cov}\left(S^{p}, f^{p}\right)}{\operatorname{var}\left(S^{p}\right)}=0$ or $\Gamma=0$ and $\gamma=0$. This is unlikely to hold in a sample of own-birth children

\footnotetext{
${ }^{17}$ An adult individual's height has been denoted "probably the best single indicator of his or her dietary and infectious disease history during childhood" (Elo and Preston, 1992).
} 
and parents. For instance, it seems likely that the education of a parent is related to certain genes of the parent. At the same time, these genes may be important predictors of the child's skills and health. Similarly, non-genetic factors, such as child-rearing talents of the parent may be related to both the education of the parent and to child outcomes. The adoption and the twin design offer two alternative ways of adressing these concerns.

\section{The adoption approach}

For adoptees, we can write the equation relating parents' education to child outcomes as:

$$
Y^{a c}=\alpha_{A D}+\delta_{A D} S^{a p}+\Gamma_{A D} g^{b p}+\gamma_{A D} f^{a p}+v^{a c}
$$

where $a c$ refers to the adopted child, $a p$ to the adoptive parent, and $b p$ to the biological parent. In this specification, only the education of one of the adoptive parents is included but in our empirical analysis, we will also employ specifications were we include the spouse's education.

In order to identify $\delta_{A D}$, the adoption literature employs two standard assumptions. First, adopted children are assumed to be randomly allocated to their adoptive parents. If the adoption agency instead would match the adoptive child with the adoptive parents, or if the education of the adoptive parents is related to characteristics of the biological parents, an artificial genetic link may be constructed and $\operatorname{cov}\left(S^{a p}, g^{b p}\right) \neq 0$. This would also be the case if adoptive parents were able to choose who to adopt and more well-educated parents would choose more healthy children or children with greater innate skills.

Holmlund et al. (2010) used data on international adoptees in Sweden and found some weak evidence of selection of adoptees. For instance, more highly educated mothers seemed to prefer older children and boys. The estimated effects were very small, however, and when controlling for these observable factors, the estimated intergenerational associations hardly changed at all. Besides controlling for observable characteristics of the adoptees, we will conduct a sensitivity analysis in order to examine whether child-parent matching is a problem in our study.

It should be noted that adoptive parents in Sweden are not able to choose a particular child for adoption. Instead, a strict procedure is followed, where the parents seeking to adopt first have to seek permission from the social authorities, who will undertake a thorough investigation about the person's or couple's ability to take care of an adopted child (SOU 2003). If granted permission, the couple can contact a government-accredited adoption organization and file an application to adopt. By choosing a particular organization, who often specialises in children from particular countries, the parents are able to choose what country to adopt from. They are also able to state a preference regarding the gender and age of the child, although there is no guarantee that this preference will be fulfilled. Thus, the parents may influence certain characteristics of the adoptive child, but these characteristics are observable to us. ${ }^{18}$

\footnotetext{
${ }^{18}$ Another worry is that the parents or the adoption centers in the home countries of the adoptees will choose adoptive parents based on certain characteristics. It is very common,
} 
The second assumption required in the adoption design is that any nongenetic characteristics of the parents, that may also directly affect the outcomes of the adopted child, are unrelated to parental schooling, i.e. that $\operatorname{cov}\left(S^{a p}, f^{a p}\right) \neq 0$. There is nothing in the adoption design that guarantees this and one can only speculate on the likely direction of the bias that arises from violating this assumption. For child-rearing skills, for instance, it is a priori not clear if such skills are negatively or positively related to parental education (Björklund et al. 2006). If there is a trade-off between investing in child-rearing skills and schooling they may be negatively related. On the other hand, education is often assumed to be related to an increased efficiency of household production, which may include child-rearing. In any case, if the second assumption needed in the adoption design is violated, the estimated "nurturing" effect would include both the effect of parental education and any other non-genetic factors that are related to both parental schooling and child outcomes.

Even if internal validity would be fulfilled in the adoption design, there are several threats to the external validity of the results. As shown in Table 1, there are large differences in the distribution of characteristics between adopted sons and own-birth sons and between own-birth parents and adoptive parents. If these differences also mean that the effect of parental education is different for adopted sons compared to own-birth sons, this would make a comparison of estimates obtained using the different designs complicated. We will therefore devote parts of the results section to investigate if there is any evidence of such differential effects. In particular, we will investigate if there is any evidence that parents treat own-birth and adopted sons differently, if adoptive families are more nurturing, and if nurturing is less effective for adopted sons, due to exposure to adverse early life conditions.

\section{The twin approach}

In the twin approach, data on monozygotic twins, who share genes and early family environment, is used. Here, the influence of such shared factors is removed by relating differences in schooling between monozygotic twin parents to differences in their children's skills and health. We may thus write the intergenerational transmission equation as:

$$
\Delta Y^{c}=\delta_{T W} \Delta S^{p}+\Gamma_{T W} \Delta g^{p}+\gamma_{T W} \Delta f^{p}+\Delta v^{c}
$$

however, that the children given up for adoption are children that have been abandoned by their mother, in which case the mother is unknown (SOU 2003). Even if the mother is known, it seems that she has little influence over the selection of adoptive parents, once she has given a written approval to the organization to adopt away her child. The adoption organization may, however, require certain conditions to be fulfilled in order to allow a couple to adopt and these requirements vary somewhat by country. In South Korea, for instance, the adoption organization only allows married couples below the age of 44 to adopt. It is also required that the marriage has lasted for at least 3 years and that the spouses have at least 11 years of schooling. In the other large adoption countries, the most important criteria seem to concern the spouses age and their marital status. For a thorough description of the various conditions demanded in the different countries, see SOU (2003). 
Since MZ twins are genetically identical, we have that $\Delta g^{p}=0 .{ }^{19}$ In order for the twin approach to provide an estimate of the causal effect, a number of additional assumptions needs to be made. In our case, the most important assumption is that schooling differences between identical twin parents are unrelated to differences in non-genetic characteristics that may also affect the outcomes of the child. To achieve this, the twin literature also assumes that $\Delta f^{p}=0$ within twin pairs. Thus, by differencing out $g^{p}$ and $f^{p}$, one may obtain an estimate of the causal effect $\delta_{T W}$. Another requirement is of course that some twin parents differ in terms of schooling, so that $\Delta S^{p}$ is not equal to zero for all twin pairs.

The assumption that schooling differences within twin pairs are unrelated to differences in unobserved non-genetic characteristics has been questioned by, for instance, Bound and Solon (1999). It would fail, for instance, if schooling differences within twin pairs are associated with differences in ability, early life health, or parenting skills. While there is mixed evidence on the topic, there are some evidence suggesting that birth weight differences between twins may be associated with schooling differences. If birth weight differences would also have an independent effect on child outcomes, twin estimates would be biased (for an overview, see Holmlund et al 2010). Moreover, in a recent paper by Lundborg et al. (2011), health differences between MZ twins, using a comprehensive set of health measures taken at age 18, did not predict schooling differences between the twins. Note, however, that even if birth weight differences would predict schooling differences among our twin parents, this is only a problem if the same birth weight differences are directly associated with the children's outcomes. ${ }^{20}$

Related to the question of unobserved differences within twin pairs is the issue of assortative mating. In the equation above, we allow the effect of parental education to also include effects that run through assortative mating. This means that we still get an unbiased estimate of the schooling of the twin parent but that the effect also includes the endowments and schooling of the spouse (Antonovics and Goldberger 2005; Holmlund et al. 2010). We will contrast the results obtained using this specification to those obtained when controlling for the education of the spouse. The latter results would then give the effect of education that does not run through assortative mating. However, since it is not possible to difference out the endowments that vary between the spouses, these results will most likely be upward biased. The reason is that higher educated parents are also more likely to marry spouses with favourable endowments, generating a positive correlation between the education of the twin parent and the error term.

Another assumption commonly made in the twin design is that measurement errors do not play an important role. As shown by Griliches (1979),

\footnotetext{
${ }^{19}$ This also requires that we exclude certain types of gene-environment interactions.

${ }^{20}$ There is very little evidence suggesting that parental birth weight has a causal effect on children's outcomes. Currie \& Moretti (2007) estimate a significant relationship between mothers' birth weight and the birth weight of their children, however, using data on siblings. For ability, we are aware of no studies that have established a causal effect of parental IQ on child IQ. In a recent working paper by Sandewall et al. (2010), however, they show that differences in the cognitive test score among MZ twins at age 18 predict differences in later schooling.
} 
the downward bias induced by normally distributed measurement errors will be exaggerated when using sibling or twin-fixed-effects models. Any reduction in the estimated coefficients when imposing sibling-fixed effects may therefore be caused by the more severe downward bias resulting from measurement errors, rather than from removal of twin-pair-specific unobserved heterogeneity. Since we rely on register data on education, we believe that the measurement error issue is less of a problem in this study. ${ }^{21}$

\section{Results}

\section{Adopted sons}

We start our analyses by estimating the relationship between parental education and child outcomes for own-birth sons and adopted sons. Table 2 shows the results, where separate regressions for mother's and father's schooling are estimated. Table 3 shows the corresponding results when controlling for spouse's education. All regressions on adoptees control for the adoptees age at immigration and country of origin.

Focusing first on the results for cognitive and non-cognitive outcomes, the significant estimates for own-birth sons suggest that one additional year of fathers' schooling increases cognitive and non-cognitive skills by .099 and .057, respectively. The corresponding estimates for mothers' education are almost identical, being .096 and .056, respectively. Moving on to the adoptees, however, the estimates are substantially reduced in magnitude. Moreover, the relative importance of fathers' versus mothers' years of schooling changes in a non-trivial way. For cognitive skills the estimate for fathers' education now decreases to .027 , while the corresponding estimate of mothers education decreases to .014, both being statistically significant at the 5 percent level.

Similar pattern as for cognitive skills are obtained for the effect of adoptive fathers' education on non-cognitive skills, where the point estimate is reduced to .017, while the corresponding estimate for mothers' education is close to zero and statistically insignificant. When we control for the spouse's education in the regressions on cognitive and non-cognitive skills, as shown in Table 3, the effect of adoption mothers' education in both cases skills approaches zero, whereas the effect of adoption father's education on cognitive and non-cognitive skills remains almost unchanged.

Our results for adoptees thus suggest that only the education of the father has a nurturing impact on the child's cognitive and non-cognitive test scores. For mothers, we interpret the association between mothers' education and children's skills to mainly reflect inherited abilities and assortative mating. The latter result is interesting, given the common finding in the adoption literature that mothers' education matter less than fathers education for children's years of schooling. One interpretation of our finding is thus that the

\footnotetext{
${ }^{21}$ Holmlund et al. (2008) addressed the measurement error problem in the Swedish data using the approach suggested by Ashenfelter and Kreuger (1994). Instrumenting the education measure with another, independent, measure of the same education did not affect the results. Moreover, Holmlund et al. (2010) found the reliability ratio in the education measure to be relatively high.
} 
larger positive effect of fathers' education on their children's education partly arises because well-educated fathers, but not well-educated mothers, improve the skills of their sons.

At this point, we can only speculate on the mechanism behind the finding that only fathers' education matters. A possible non-causal explanation would be that there exists a negative correlation between child-rearing skills and education among mothers but not among fathers. ${ }^{22}$ Another explanation could be that the result reflects specialization within the household, where fathers take a greater responsibility for helping with tasks that improve children's cognitive and non-cognitive skills, whereas mothers take a greater responsibility for other household work. Yet another explanation could be that there is a stronger correlation between education and income for fathers than for mothers, so that the effect of fathers' education also picks up the effect of income to a greater extent. ${ }^{23}$ We can test this by including controls for income in the regressions. This only marginally affected the estimates for parents' education and the decline in the size of the coefficients was almost identical for mothers and fathers. ${ }^{24}$

The relative importance of fathers' versus mothers' education is not as straightforward when considering our health outcomes. Although fathers' education seems to matter more than mothers' education for the overall health of their for own-birth sons, this result does not hold up in the sample of adoptees. Here, mothers' education is associated with a greater increase in health and the effect is significant at the 10 percent level, although it should be noted that the difference in point estimates between mothers and fathers is rather small. The gender difference becomes more pronounced, however, when accounting for spouses education, where the point estimate of fathers' education is halved in magnitude. These results cast some doubts on the hypothesis that there is a negative correlation between child-rearing skills and mothers' education. Rather, the result suggests that fathers and mothers specialize in different aspects of child-rearing and that education is generally beneficial for the various child outcomes considered.

For our other measure of early life health, height, the results for own-

\footnotetext{
${ }^{22} \mathrm{~A}$ downward bias would also arise if there is a negative correlation between education and certain favorable unobserved characteristics in the sample of adoptive parents (Black et al. 2010). The reason is that adoptive parents who are allowed to adopt despite poor observable characteristics are likely to have better on average unobserved characteristics that compensate for their poor observable characteristics. This would imply that the estimated effect for the sample of adoptive parents is downward biased. If the negative correlation between education and favourable unobserved characteristics is stronger for mothers than fathers, one reason being that the screening procedure prior to adoption may put more emphasis on mothers' characteristics, this could explain why the estimated effects are smaller for mothers. There is nothing in the formal guidelines for adoption, however, which supports such a differential treatment of males and females.

${ }^{23}$ Yet another explanation for the result that fathers' education matters more would be that measurement errors are more severe for the measure of mothers' years of schooling. Since our measures are based on register data, we see no reason why this would be the case in our study. Moreover, Holmlund et al. (2008) report that the reliability ratio for education in these register is 0.95 for both mothers and fathers.

${ }^{24}$ For cognitive skills, the effects of fathers and mothers education declined to .022 and .009 when controlling for income. The corresponding estimates for non-cognitive skills were .013 and .000 .
} 
birth sons suggest that mothers' education are of somewhat more importance. In the sample of adopted sons, however, the education of the father matters more, with an estimate that is significant at the 10 percent level. This result is strengthened when accounting for assortative mating, where the estimate of mothers' education approaches zero. In sum, the results for health outcomes are more mixed when it comes to the relative importance of mothers' and fathers' education, although the results suggest small but significant nurturing effects.

As discussed in the methods section, a crucial assumption in the adoption design is that adopted children are randomly allocated to their adoptive parents. Before proceeding with the results for twins, we shed some light on the credibility of this assumption by regressing parental education on various observable characteristics of the adopted children. The results, reported in Table 4, suggest that some matching appears to be take place, since 4 out of 12 coefficients from the regressions come out as significant. The magnitudes of the coefficients are quite small, however.

The results suggest, for instance, that parental education is positively and significantly related to the probability of adopting a child from Columbia. On the other hand, there is a negative correlation between parents' education and the probability of being adopted from South Korea. Since children from South Korea outperforms even Swedish-born children in some of the enlistment tests, this rather suggests that, if anything, some negative selection is present.

Further evidence that the magnitude of the matching is limited is revealed by the fact that controlling for country of birth in the regressions in Table 2 does not change the results to any important extent. In fact, some of the resulting estimates for the adopted children becomes somewhat stronger in magnitude, which is what one would expected if there is negative relation between parental education and the probability of adopting a child from "highquality" countries.

For age at adoption, we do not find any significant relationship with parental education. In sum, we believe that the results presented in Table 4 do not suggest any problematic matching that we cannot deal with. We also note that our results on potential non-random allocation of adoptees are similar to the results found in Holmlund et al. (2010), where there was no evidence of any important parent-child matching.

\section{Sons with a monozygotic twin parent}

We continue to explore the intergenerational transmission of human capital using the twin design. The results are shown in Table 2, where we also include the OLS results for the twin sample in order to get some idea about the representativeness of the twin sample. Ideally, the OLS estimates should not differ by large compared to the result for the main sample of own-birth children, which is also what most of the results in Table 2 suggest. For cognitive skills, for instance, the own-birth estimates of fathers' and mothers' education are .099 and .096, which is very similar to the OLS estimates obtained for the twin sample of .097 and .100, respectively.

Moving on to the twin fixed-effect results, and starting with cogni- 
tive skills, the results suggest a similar 'nurturing' effect of both mothers' and fathers' education of .050 and .044, respectively. For fathers, this estimate is rather similar to the corresponding estimate obtained in the sample of adoptees. For mothers, the differences are somewhat larger, although one should note that the point estimates are quite small in both cases and one should thus not exaggerate the differences. The results for cognitive skills do not change much when controlling for spouse's education, as shown in Table 5. Note that this result differs from the result obtained for adoptive mothers, where the effect approached zero when accounting for the spouse's education.

The results for non-cognitive skills are much in line with the results obtained for the adoptees. While the OLS estimates on the twin sample suggest an equal effect of mothers' and fathers' education on their children's non-cognitive skills, the fixed effects estimates again suggest that the father's education matters more. An additional year of schooling increases the noncognitive test results by .041 , whereas the corresponding estimate for mothers is .019 and insignificant. Accounting for spouse's education does, again, not change this pattern.

For our overall health measure, the twin-based estimates again suggest that mothers' education matters more. While the OLS estimates suggests an equal effect of twin mothers' and twin fathers' schooling, the fixed effects estimates are only significant for twin mothers, in line with the results obtained for adoptees. Moreover, the estimated coefficient differs substantially from that of fathers, which is small and has the wrong sign. The estimate, 0.168, suggests that one additional year of mother's schooling increases the child's health with about 5 percent of a standard deviation. For height, the estimates are roughly halved in magnitude when imposing fixed effects and similar, but imprecisely measured, for twin fathers and twin mothers. None of these results change to any dramatic extent when accounting for spouse's education.

\section{Comparing the adoption and twin estimates}

In sum, the results obtained using both the twin sample and adoptee sample suggest that cognitive skills, non-cognitive skills, and health may be an important mechanism through which the intergenerational transmission of schooling arises. For most outcomes studied, the results are relatively similar across the research designs, despite the fact that the samples are very different and that very different assumptions are used. A general picture that emerges is that fathers' education seems to matter somewhat more for the development of their son's skills, whereas mothers' education matters more for the development of their health. Since it is rather well established that early life skills and health affect later educational attainment, our results thus provide some clues to what the underlying mechanisms behind the transmission of human capital are.

Even though the results came out remarkably similar across research designs, there is a tendency towards smaller magnitudes in the sample of adoptees. Moreover, an often expressed concern is that the external validity of adoption estimates may be low. Adoptive parents may, for various reasons, be more or less effective in bringing skills to their adopted children compared 
to biological parents. There could also be something that makes adopted children gain less skills from having well-educated children compared to children of twin parents. We will next address some hypotheses that may affect the external validity of the adoption results.

First, we examine differences in the distribution of characteristics between the group of adoptees, sons of twin parents, and own-birth children. Clearly, both adoptive parents and adoptees differ from the other groups in many ways, as revealed by the descriptive statistics in Table 1 . First of all, adoptive parents are on average more highly educated. Adoptive fathers and mothers have on average 12.7 and 12.8 years of schooling, compared to 10.6 years for twin parents. At the same time, adoptees on average score substantially worse on the skills tests during the enlistment compared to sons of twin parents.

Given the rather substantial differences in the distribution of characteristics between the adoption and twin sample, it becomes even more surprising to find the effects of education on skills and health to be rather similar across the designs. This suggests that the effects of parental schooling are not radically different across the different groups considered. We will further check, however, the external validity of the adoption result, which will also shed some light on possible reasons for the difference in the magnitude of the estimates obtained in the adoption and the twin design

In order to investigate if adoptive parents are more or less nurturing compared to other parents, we can compare the effect of education for ownbirth sons with an adopted sibling with the effect for own-birth sons without an adopted sibling (see e.g. Plug 2004; Holmlund et al. 2010). If adoptive parents are more nurturing, we would expect a greater effect for own-birth children with an adopted sibling compared to the effect on own-birth children without an adopted sibling.

For fathers, the effect of parents' education on the biological child's cognitive skills, is more or less the same, whether or not the child has an adopted sibling (Table A1). For mothers, however, the estimate is about double in size if the child has an adopted sibling. A similar increase in the magnitude of the effect is obtained for health. These results are consistent with the idea that that adoptive mothers are more nurturing than biological mothers. ${ }^{25}$ On the other hand, the effect on height is now halved in magnitude and we therefore refrain from any definitive statements about the whether adoptive mothers and fathers are more or less nurturing.

An alternative interpretation of the results above is that mothers who adopt a child invest less in their biological child and more in the adopted child. We further test for any evidence that parents treat adopted children differently from own-birth children by comparing the effect of parental education for adopted sons with an own-birth sibling to the corresponding effect for those without a own-birth sibling (Table A2). If the latter effect is greater, this would support the idea that parents treat adopted children worse. We obtain no strong evidence for this hypothesis, since the resulting point estimates for most

\footnotetext{
${ }^{25}$ Note, however, that we now rely on a different sample, where we cannot rule out that the effects for families with only own-birth children would also have been different.
} 
outcomes are rather similar in both types of families and since the estimates are imprecisely estimated in the mixed families. These findings support those obtained in previous studies, such as Björklund et al. (2006) and Holmlund et al. (2010).

Finally, we test for any signs that nurturing is less effective for adopted sons compared to own-birth sons. The idea here is that those adopted early are less exposed to detrimental conditions in their home country, which means that nurturing may be more effective. ${ }^{26}$ By comparing the effects to those who were adopted at later ages, we can get some indications if nurturing is less effective for those adopted late. For cognitive skills, we do not obtain any large differences in the results for those adopted before and after the age of 1 , neither for mothers, nor for mothers (Table A3).

For non-cognitive skills, the effect of fathers' education is smaller for those adopted later, although one should note that the absolute difference in point estimates is not great. The greatest difference is obtained for overall health, where the effect of both mothers' and fathers' education is substantially greater if the child was adopted before the age of 1 . This supports the idea that parental education has less of an effect on health if the child had been exposed to adverse living conditions early in life. For those adopted before the age of 1, both mothers and fathers' schooling show a positive impact on the child's health, although the effect of mothers' schooling is still greater. For our height measure, our estimates are imprecise, although the point estimates are actually slightly larger for those arriving later.

To sum up, we have shown that although the characteristics of the adoptive parents and adoptees differ greatly from those of the other samples used, we obtain rather few indications that the effect of parents' schooling differ greatly between adoptive parents and twin parents. The clearest result was obtained for health, were the sensitivity analysis supported the hypothesis that parents' schooling has less of an effect if the adopted child was adopted late. This may also explain some of the smaller effect on health obtained for adoptees compared to children of twin parents. We leave this to future research to further explore.

\section{Are earlier grades and tracking affecting child skills and health at $18 ?$}

Our results so far are consistent with the idea that parental education matters for children's education partly because parental education improves children's skills. One could not rule out the possibility, however, that child skills, as measured at age 18, are affected by earlier study results or choice of track in school, so that parental education affects children's skills by improving their study outcomes. We analyzed this by analyzing the link between parental education and children's grades for the subsample on which we have grade information. The results showed small and insignificant effect for grades in

\footnotetext{
${ }^{26}$ Evidence from Romanian adoptees adopted to UK, for instance, suggests that if the adoption took place during the first 6 months of life, catch-up in terms of height and IQ was almost complete (Rutter et al. 1998). For those adopted later, catch-up was less, but still substantial.
} 
language and mathematics at age 15 , however.

\section{How large are the effects and how do they relate to previous find- ings?}

The estimates we obtain in the adoption and twin design may appear rather small, but so are also the previous estimates on the effect of parents' education on children's education that have been obtained in Scandinavian countries. But are our results reasonable, given the previous estimates on the intergenerational transmission of human capital? We can shed some light on this, by examining to what extent our estimates, together with previous estimates on the returns to skills, could generate the observed transmission of schooling.

Starting with cognitive skills and twins, our twin-based estimates for fathers and mothers schooling converge around 0.05 in most specifications. This means that one additional year of fathers' schooling is associated with a 5 percent of a standard deviation increase in the child's cognitive skills. Sandewall et al. (2010) provide twin-based estimates of the returns to cognitive skills and Lundborg et al. (2011) provides twin-based estimates on the returns to both non-cognitive and cognitive skills, where in both studies a one standard deviation increase in cognitive skills is associated with about 0.5 additional years of schooling. This means that a 5 percent of a standard deviation increase in cognitive skills, which resulted from one additional year of parental schooling, is associated with 0.025 additional years of schooling by the child.

If we assume a similar return to non-cognitive skills, as indicated by the results of Lundborg et al. (2011), and take our estimated effect where one additional year of fathers' schooling is associated with a 4 percent of a standard deviation increase in non-cognitive skills, this would imply a .020 increase in years of schooling of the child. Since previous twin-based estimates of the effect of fathers' schooling on children's schooling obtained in Scandinavian countries are often found to be in the ballpark of .06 - .10, our results for cognitive and non-cognitive skills would thus be able to explain a large part of this causal transmission of schooling across generations. This is reassuring and makes our estimates appear very reasonable.

Finally, we may use our estimates to say something about the policy relevance of our results. If we assume that one additional year of parental schooling increases the child's skills in a way that makes him obtain about 0.05 additional years of schooling, this also means that 3 additional year of schooling, equivalent to a bachelor degree, would increase child schooling by about 0.15 years, if we assume linear returns. Since previous studies, such that Lundborg et al. (2009), have established that the wage returns to years of schooling in Sweden is about 6 percent, this would increase yearly income increase by almost 1 percent. One a life-time basis, this is not trivial. Since we show, however, that skills are most likely an important mechanism through which the transmission of human capital arises, the beneficial effects of parents' education are most likely not restricted to income but translates into other areas as well. Previous studies on the social returns to early life skills, such as Heckman et al. (2006), have shown that increases in non-cognitive skills leads to decrease in crime among other things. This means that although 
the effect of one additional year of parents' schooling on one particular child outcome may be small, the total effect added up over different outcomes may be substantial.

\section{Summary and conclusion}

A recent literature, using an adoption and twin design, has established that the intergenerational transmission of education partly reflects a causal effect of parents' education. In this paper, we provide some clues regarding what it is that well-educated parents bring to their children, so that their children obtain more education. We focused on factors such as early life skills and health that could plausibly be important mechanisms for the intergenerational transmission of education and employed the most common methods used in the recent literature; the adoption and the twin design.

Our results suggest that cognitive and non-cognitive skills, as well as health, may be important factors in understanding the intergenerational transmission of human capital. In both the adoption and the twin design, parents' schooling had a positive impact on these child outcomes and the estimates were rather similar across the twin and adoption designs. Our results also suggest that fathers' education was of greater importance for the development of the child's cognitive and non-cognitive skills, whereas mothers' education matter more for the child's health. Since it is well established that early life skills and health affects later educational attainment, our results thus suggest that part of the causal effect of parental schooling on children's schooling reflects an effect of parental schooling on children's skills and health.

We believe that our estimates appear very reasonable, given the previous estimates using an adoption and a twin design that estimate the intergenerational transmission of schooling in Scandinavian countries. Using our estimates of the effect of fathers' schooling on skills, and in addition using previous findings on the returns to skills, we showed that our estimates nicely fitted in with those obtained for the transmission of education in previous adoption and twin studies in Scandinavian countries. Moreover, we showed that although small, the estimated effects are far for trivial, especially when one considers that an increase in various types of skills, as well as health, most likely has positive effects on a far wider range of outcomes than just earnings.

Returning to some of the policy issues discussed in the introduction, our results suggest that interventions that increase the level of schooling in society may have benefits that not only transcends across generations but also across a range of child outcomes. This is a useful finding since education is something that can be manipulated by policy-makers. We believe that a fruitful path for future research will be to continue to try to understand the mechanisms behind the intergenerational transmission of human capital. 


\section{References}

Almond, D \& Currie, J. 2010. "Human Capital Development Before Age Five," NBER Working Papers 15827, National Bureau of Economic Research.

Amin, V., Lundborg, P., Rooth, DO (2011a). Mothers' do matter: New evidence on the effect of parents' schooling and children's schooling using Swedish twin data. IZA Discussion Paper No. 5946.

Amin, V., Lundborg, P., Rooth, DO (2011b). Following in your father's footsteps: A note on the intergenerational transmission of income between twin fathers and their sons. IZA Discussion Paper No. 5990.

Anger, Silke and Guido Heineck (2009), "Do Smart Parents raise smart children? The intergenerational transmission of cognitive abilities", Working paper no. 156 (SOEP, DIW, Berlin).

Antonovics, Kate and Arthur S. Goldberger. 2005. "Does Increasing Women's Schooling Raise the Schooling of the Next Generation? Comment." American Economic Review, 95(5): 1738-1744.

Ashenfelter, Orley and Alan B. Krueger. 1994. "Estimates of the Returns to Schooling from a New Sample of Twins." American Economic Review, 84(5): 1157-1173.

Behrman, Jere R. and Mark R. Rosenzweig (2002), "Does increasing women's schooling raise the schooling of the next generation?" American Economic Review 92:323-334.

Bingley, P., Christensen, K., \& Jensen, V. M. (2009). Parental Schooling and Child Development: Learning from Twin Parents. SFI working paper.

Björklund, A., Jäntti, M. and Solon, G., 2005, "Influences of Nature and Nurture on Earnings Variation: A Report on a Study of Various Sibling Types in Sweden". In Unequal Chances: Family Background and Economic Success, edited by Bowles, S., Gintis, H. and Osborne Groves, M., Princeton: Princeton University Press, pp. 145-164.

Björklund, A., Lindahl, M. and Plug, E., 2006, "The Origins of Intergenerational Associations: Lessons from Swedish Adoption Data", Quarterly Journal of Economics 121, pp. 999-1028.

Björklund, A. and Salvanes, K. (2010). Education and Family Background: Mechanisms and Policies. In: E.A. Hanushek, S. Machin, and L. Woessmann (eds.), Handbook in Economics of Education, Vol. 3, North Holland: pp. 201-247.

Björklund Anders, Karin Hederos Eriksson, and Markus Jäntti (2010), "IQ and family background: Are associations strong or weak?" The B.E. Journal of Economic Analysis and Policy (Contributions) 10(1).

Black, S., Devereux, P. and Salvanes, K., 2005, "Why the Apple Doesn't Fall Far: Understanding Intergenerational Transmission of Human Capital", American Economic Review 95(1), pp. 437-449.

Black, Sandra, Paul Devereux, and Kjell Salvanes (2009), "Like father, like son? A note on the intergenerational transmission of IQ scores", Economics Letters 105: 138-140.

Black, SE, Devereux, P. (2010). Recent Developments in Intergenerational Mobility. Forthcoming in: O. Ashenfelter and D. Card (eds.), Handbook of Labor Economics, Amsterdam: Elsevier. 
Bound, J. and Solon, G., 1999, "Double trouble: on the value of twinsbased estimation of the return to schooling", Economics of Education Review, 18(2), pp. 169-192.

Breierova, L. \& Esther Duflo, 2004. "The Impact of Education on Fertility and Child Mortality: Do Fathers Really Matter Less Than Mothers?," NBER Working Papers 10513, National Bureau of Economic Research,

Carneiro, Pedro, Costas Meghir, and Matthias Parey. 2007. "Maternal Education, Home Environments. and the Development of Children and Adolescents." Institute of Fiscal Studies Working Paper W07/15.

Chen, Y, Li, H. (2009). Mother's education and child health: Is there a nurturing effect? Journal of Health Economics: 28(2): 413-426.

Chevalier, Arnaud, and Vincent O'Sullivan. 2007. "Mother's Education and Birth Weight." IZA Discussion Paper 2640.

Chevalier, Arnaud. 2004. "Parental Education and Child's Education: A Natural Experiment", IZA discussion paper No. 1153.

Chou, Shin-Yi, Jin-Tan Liu, Michael Grossman, Theodore Joyce. 2007. "Parental Education and Child Health: Evidence from a Natural Experiment in Taiwan." NBER Working Paper No. 13466.

Currie, J (2009). "Healthy, Wealthy, and Wise: Socioeconomic Status, Poor Health in Childhood, and Human Capital Development," Journal of Economic Literature, vol. 47(1), pages 87-122

Currie, Janet. and Enrico Moretti 2003. "Mother's Education and the Intergenerational Transmission of Human Capital: Evidence from College Openings," Quarterly Journal of Economics VCXVIII: 1495-1532.

Currie, Janet. and Enrico Moretti (2007). "Biology As Destiny? Short and Long-Run Determinants of Intergenerational Transmission of Birth Weight" Journal of Labor Economics, 25(2): 231-264.

Dearden, Lorraine S., Stephen Machin and Howard Reed. (1997). "Intergenerational Mobility in Britain." Economic Journal, 110(440): 47-64.

Elo, I.T. and S.H. Preston. 1992. "Effects of early-life conditions on adult mortality: a review." Population index, 58, 186-212.

Griliches, Zvi (1979), "Sibling Models and Data in Economics: Beginnings of a Survey," Journal of Political Economy, University of Chicago Press, vol. 87(5), pages S37-64.

Grönqvist, Erik, Björn Öckert, and Jonas Vlachos (2009), "The Intergenerational transmission of cognitive and non-cognitive abilities." CEPR Discussion Paper 7908.

Hægeland, Torbjørn, Lars Kirkebøen, Oddbjørn Raaum and Kjell Salvanes. 2010. "Why Children of College Graduates Outperform their Schoolmates: A study of Cousins and Adoptees." Mimeo, University of Bergen.

Heckman, J., Stixrud, J. and S. Urzua. 2006. "The Effects of Cognitive and Noncognitive Abilities on Labor Market Outcomes and Social Behavior." Journal of Labor Economics 24(3):411-482.

Holmlund, Helena, Mikael Lindahl and Erik Plug. 2008. "The Causal Effect of Parent's Schooling on Children's Schooling: A Comparison of Estimation Methods." IZA Discusson Paper No. 3630.

Holmlund H, Lindahl, M, Plug, E. (2010), The Causal Effect of Parents' Schooling on Children's Schooling: A Comparison of Estimation Methods. 
forthcoming Journal of Economic Literature.

Lichtenstein, Paul, Ulf de Faire, Birgitta Floderus, Magnus Svartengren, Pia Svedberg and Nancy L. Pedersen (2002), "The Swedish Twin Registry: A unique resource for clinical, epidemiological and genetic studies", Journal of Internal Medicine, 252: 184-205.

Lindeboom, M., van der Klaauw, B., Nozal, AL. (2009). Parental education and child health: evidence from a schooling reform. Journal of Health Economics 28, 109-131.

Lindqvist, M., and Hjalmarsson, R. (2010). Driving Under the Influence of Our Fathers. The B.E. Journal of Economic Analysis \& Policy 10(1): 1-15.

Lindqvist, M., and Hjalmarsson, R. (2011a). Like Godfather, Like Son: Explaining the Intergenerational Nature of Crime. Forthcoming in Journal of Human Resources.

Lindqvist, M., and Hjalmarsson, R. (2011b). The Origins of Intergenerational Associations in Crime: Lessons from Swedish Adoption Data" CEPR Discussion Paper No. 8318, April 2011.

Lindqvist, E., Vestman, R. (2010). The Labor Market Returns to Cognitive and Noncognitive Ability: Evidence from the Swedish Enlistment" forthcoming in American Economic Journal: Applied Economics.

Lundborg, P., Nystedt, P., Rooth, DO. (2009). The Height Premium in Earnings: The Role of Cognitive Ability and Physical Strength. IZA Working Paper 4266.

Lundborg, P., Nilsson, A., Rooth, D. (2011). Does Health Predict Schooling Differences Within Monozygotic Twin Pairs? IZA Discussion Paper No. 503.

McCrary, J., Royer, H. (2011). "The Effect of Maternal Education on Fertility and Infant Health: Evidence from School Entry Policies Using Exact Date of Birth" American Economic Review, forthcoming.

Plug, E., 2004, "Estimating the Effect of Mother's Schooling on Children's Schooling Using a Sample of Adoptees", American Economic Review 94(1), pp. 358-368.

Plug, E. and Vijverberg, W., 2003, Schooling, Family Background, and Adoption: Is It Nature or Is It Nurture?", Journal of Political Economy, 111(3), pp. 611-641.

Plug, E. and Vijverberg, W., 2005, "Does Family Income Matter for Schooling Outcomes? Using Adoptees as a Natural Experiment", Economic Journal 115(506), pp. 879-906.

Pronzato, Chiara. (2010) "An Examination of Paternal and Maternal Intergenerational Transmission of Schooling." Forthcoming in Journal of Population Economics.

Rutter, M. et al. (1998), Developmental catch-up, and deficit, following adoption after severe global early privation, Journal of Child Psychology and Psychiatry, 39, 465-476.

Sacerdote, Bruce. 2000. "The Nature and Nurture of Economic Outcomes." NBER Working Paper 7949.

Sacerdote, B., 2002, "The Nature and Nurture of Economic Outcomes," American Economic Review Papers and Proceedings, 92(2), 344-348.

Sacerdote, Bruce (2007), "How large are the effects from changes in family 
environment? A study of Korean American adoptees", Quarterly Journal of Economics 122: 119-157.

Sandewall, Ö., Cesarini, D., Johannesson, M., 2009. The Co-Twin Methodology and Returns to Schooling - Testing a Critical Assumption. IFN Working Paper no. 806, IFN, Stockholm.

SOU, 2003, "Adoptionsutredningens betänkande Adoption - till vilket pris?", SOU 2003:49. 
Table 1: Descriptive statistics. Data from the Swedish twin registry.

\begin{tabular}{lcccccc}
\hline \hline & \multicolumn{2}{c}{ Own-birth sons } & \multicolumn{2}{c}{ Adopted sons } & \multicolumn{2}{c}{ Son of twins } \\
\cline { 2 - 7 } & Mean & St. dev & Mean & St. dev & Mean & St. dev \\
\hline Cognitive ability & 5.20 & 1.90 & 4.22 & 1.91 & 5.24 & 1.83 \\
Non-cognitive ability & 5.19 & 1.66 & 4.74 & 1.71 & 5.33 & 1.59 \\
Health & 2.69 & 4.23 & 4.20 & 4.8 & 2.22 & 3.69 \\
Height & 179.6 & 6.48 & 170.2 & 6.59 & 179.68 & 6.19 \\
Age at adoption & & & 1.69 & 1.92 & & \\
Father's education & 1.69 & 1.92 & 12.69 & 2.73 & 10.56 & 3.12 \\
Mother's education & 11.49 & 2.30 & 12.80 & 2.61 & 10.63 & 2.71 \\
\hline
\end{tabular}

Notes: This table reports descriptive statistics. 


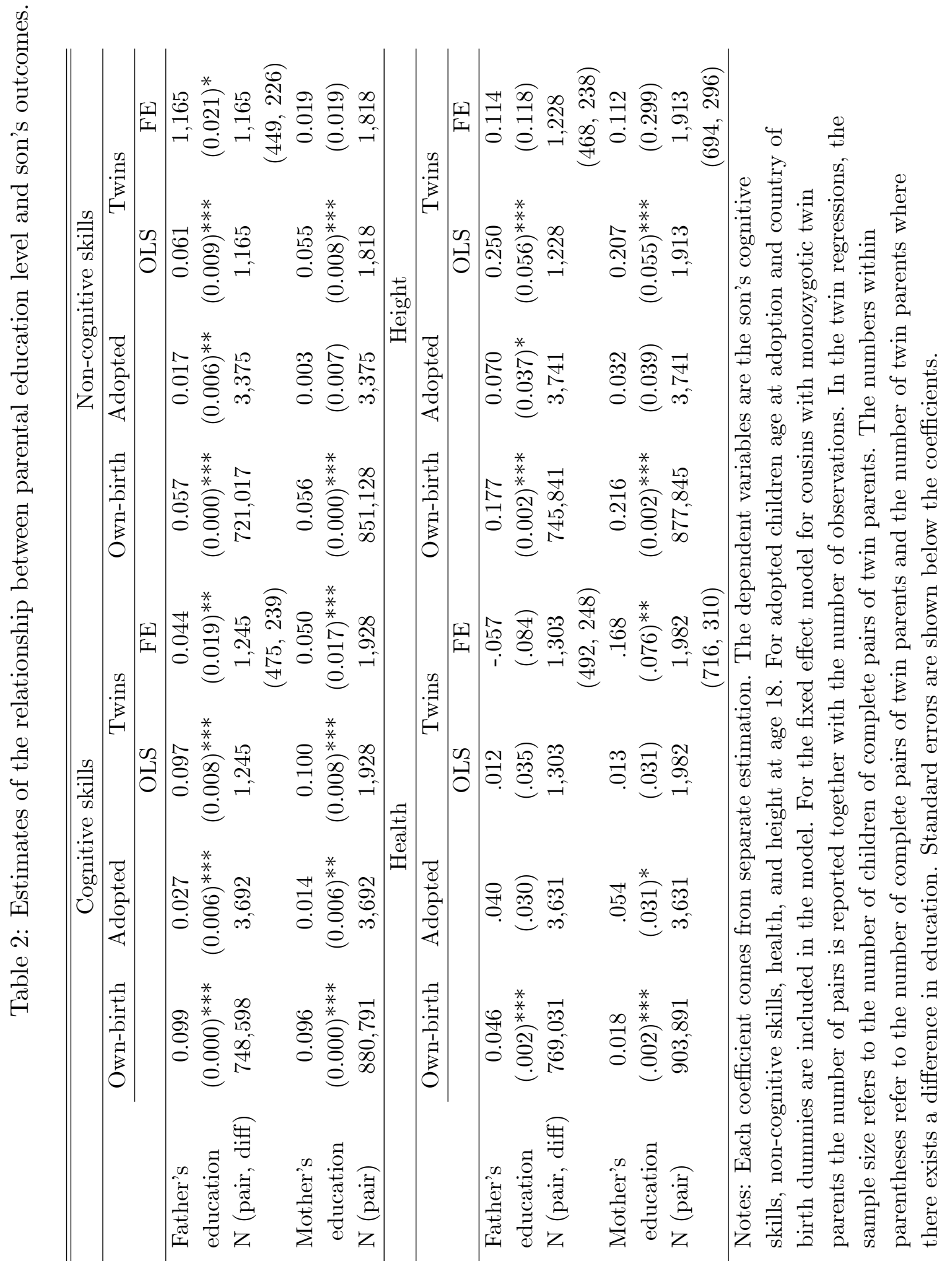


Table 3: Estimates of the relationship between parental education level and son's outcomes when accounting for assortative mating. Adopted sons.

\begin{tabular}{lcccc}
\hline \hline & Cognitive & Non-cognitive & Health & Height \\
\hline Father's education & 0.027 & 0.021 & .019 & 0.073 \\
& $(0.006)^{* * *}$ & $(0.007)^{* *}$ & $(.034)$ & $(0.043)^{*}$ \\
Mother's education & -0.001 & -0.008 & .044 & -0.007 \\
& $(0.007)$ & $(0.008)$ & $(.036)$ & $(0.045)$ \\
$\mathrm{N}$ & 3,692 & 3,375 & 3,631 & 3,741 \\
\hline
\end{tabular}

Each coefficient comes from separate estimation. The dependent variables are the son's cognitive skills, non-cognitive skills, health, and height at age 18.

from linear OLS and FE regressions. For adopted children age at adoption and country of birth dummies are included in the model. Standard errors are shown below the coefficients. 
Table 4: Estimating the relationship between parental education level and country of birth and age at adoption.

\begin{tabular}{cccccccc}
\hline \hline & Chile & Columbia & India & South Korea & Sri Lanka & Thailand & Age adopted \\
\hline Father's education & .002 & .003 & .001 & -.007 & -.005 & -.002 & -.016 \\
& $(.002)$ & $(.002)^{*}$ & $(.002)$ & $(.003)^{* *}$ & $(.002)^{* * *}$ & $(.002)$ & $(.013)$ \\
Mother's education & -.003 & .005 & .001 & -.012 & .003 & .000 & .004 \\
& $(.002)$ & $(.002)^{* *}$ & $(.003)$ & $(.003)^{* * *}$ & $(.002)^{*}$ & $(.002)$ & $(.014)$ \\
\hline
\end{tabular}

Notes: The dependent variable is shown in the top of the column. A linear probability model is estimated. Standard errors in parenthesis. 
Table 5: Estimates of the relationship between parental education level and son's outcomes when accounting for assortative mating. Twin fathers and mothers.

\begin{tabular}{lcccc}
\hline \hline & Cognitive & Non-cognitive & Health & Height \\
\hline Twin fathers & & & & \\
Twin father's education & 0.033 & 0.041 & -0.055 & 0.115 \\
& $(0.019)^{*}$ & $(0.022)^{*}$ & $(.061)$ & $(0.119)$ \\
Mother's education & 0.056 & 0.001 & -0.009 & 0.000 \\
& $(0.016)^{* * *}$ & $(0.019)$ & $(0.073)$ & $(0.102)$ \\
$\mathrm{N}$ & $1,245(475)$ & $1,165(449)$ & $1,303(492)$ & $1,228(468)$ \\
& & & & \\
\hline Twin mothers & & & \\
Twin father's education & 0.052 & 0.038 & 0.067 & 0.139 \\
& $(0.013)^{* * *}$ & $(0.016)^{* *}$ & $(.061)$ & $(0.081)^{*}$ \\
Mother's education & 0.043 & 0.013 & 0.159 & 0.092 \\
& $(0.017)^{* * *}$ & $(0.019)$ & $(.076)^{* *}$ & $(0.100)$ \\
$\mathrm{N}$ & $1,928(698)$ & $1,818(661)$ & $1,982(716)$ & $1,913(694)$
\end{tabular}

Notes: The dependent variables are the son's cognitive skills, non-cognitive skills, health, and height at age 18. Standard errors are shown below the coefficients. 
Table 6: The effect of parental education for own-birth sons with an adopted sibling.

\begin{tabular}{lcccc}
\hline \hline & Cognitive & Non-cognitive & Health & Height \\
\hline Father's education & 0.058 & 0.015 & 0.033 & 0.111 \\
& $(0.009)^{* * *}$ & $(0.009)$ & $(0.042)$ & $(0.070)$ \\
Mother's education & 0.097 & 0.018 & 0.049 & 0.105 \\
& $(0.009)^{* * *}$ & $(0.010)^{*}$ & $(0.047)$ & $(0.068)$ \\
$\mathrm{N}$ & 1,444 & 1,389 & 1,278 & 1,450 \\
\hline
\end{tabular}

Notes: In all columns age at adoption and country of birth dummies are. included in the modelStandard errors are shown below the coefficients. 
Table 7: The effect of parental education for adopted sons with a biological sibling.

\begin{tabular}{lcccc}
\hline \hline & Cognitive & Non-cognitive & Health & Height \\
\hline Father's education & 0.016 & 0.020 & 0.002 & 0.097 \\
& $(0.011)$ & $(0.013)$ & $(0.063)$ & $(0.077)$ \\
Mother's education & 0.019 & 0.012 & 0.037 & -0.049 \\
& $(0.012)$ & $(0.014)$ & $(0.069)$ & $(0.085)$ \\
$\mathrm{N}$ & 819 & 754 & 797 & 823 \\
\hline
\end{tabular}

Notes: In all columns age at adoption and country of birth dummies are. included in the modelStandard errors are shown below the coefficients. 


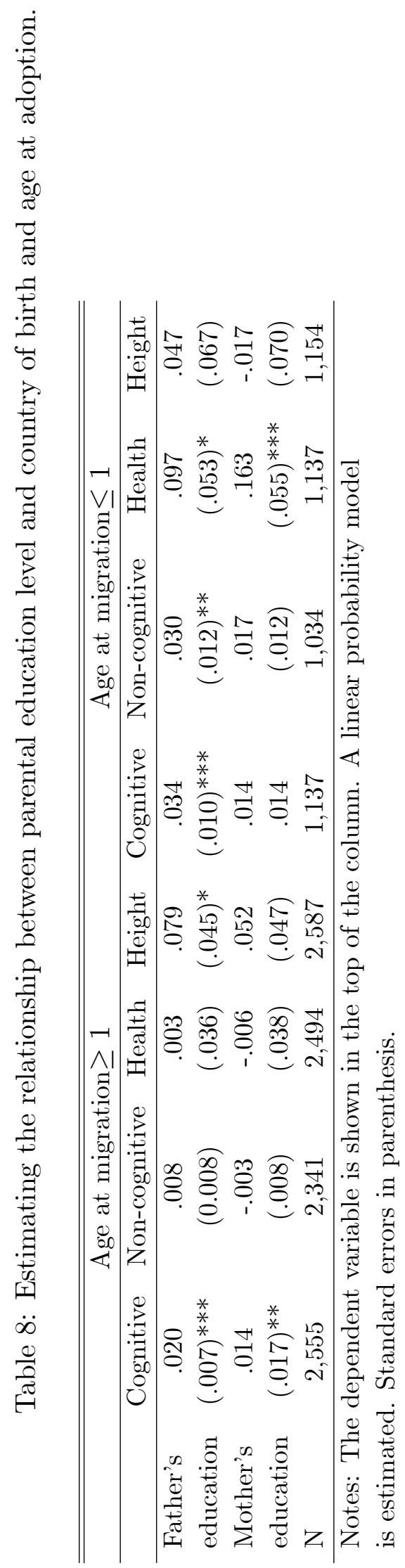

